\title{
Pacific Decadal Variability: Paced by Rossby Basin Modes?
}

\author{
WILBERT WEIJER \\ Los Alamos National Laboratory, and New Mexico Consortium, Los Alamos, New Mexico \\ ERNESTO MUÑOZ* \\ New Mexico Consortium, Los Alamos, New Mexico \\ NIKLAS SCHNEIDER \\ University of Hawaii at Manoa, Honolulu, Hawaii \\ FRANÇOIS PRIMEAU \\ University of California, Irvine, Irvine, California
}

(Manuscript received 5 June 2012, in final form 31 July 2012)

\begin{abstract}
A systematic study is presented of decadal climate variability in the North Pacific. In particular, the hypothesis is addressed that oceanic Rossby basin modes are responsible for enhanced energy at decadal and bidecadal time scales. To this end, a series of statistical analyses are performed on a 500-yr control integration of the Community Climate System Model, version 3 (CCSM3). In particular, a principal oscillation pattern (POP) analysis is performed to identify modal behavior in the subsurface pressure field.

It is found that the dominant energy of sea surface temperature (SST) variability at $25 \mathrm{yr}$ (the model equivalent of the Pacific decadal oscillation) cannot be explained by the resonant excitation of an oceanic basin mode. However, significant energy in the subsurface pressure field at time scales of 17 and 10 yr appears to be related to internal ocean oscillations. However, these oscillations lack the characteristics of the classical basin modes, and must either be deformed beyond recognition by the background circulation and inhomogeneous stratification or have another dynamical origin altogether. The 17-yr oscillation projects onto the Pacific decadal oscillation and, if present in the real ocean, has the potential to enhance the predictability of low-frequency climate variability in the North Pacific.
\end{abstract}

\section{Introduction}

The Pacific climate system exhibits variability on decadal time scales, known as Pacific decadal variability (PDV). This variability is conveniently associated with a specific signature in sea surface temperature (SST) known as the Pacific decadal oscillation (PDO), which is defined as the leading empirical orthogonal function

\footnotetext{
* Current affiliation: National Center for Atmospheric Research, Boulder, Colorado.

Corresponding author address: Wilbert Weijer, Los Alamos National Laboratory, CCS-2, MS B296, Los Alamos, NM 87545. E-mail: wilbert@lanl.gov
}

(EOF) of North Pacific SST variability (Mantua et al. 1997).

Although many hypotheses have been put forward to explain PDV, most of these assign the long-term memory of PDV to the ocean (e.g., Miller and Schneider 2000). The so-called null hypothesis is that low-frequency variability reflects the inert response of the ocean circulation to synoptic variability of the atmosphere. Both stochastic heat flux and wind stress forcing have been put forward as candidates to drive this process (e.g., Hasselmann 1976; Frankignoul and Hasselmann 1977; Frankignoul et al. 1997). Indeed, simple Rossby wave models forced with observed winds stress show significant skill in reproducing low-frequency variability in the Kuroshio-Oyashio Extension (KOE) region (e.g., Schneider and Miller 2001; Qiu 2003; Qiu and Chen 
2005). Alternative hypotheses necessarily have to show that the climate system exhibits enhanced variance in certain frequency bands that cannot be explained by this simple stochastic explanation.

Although the observational climate record is relatively short for identifying low-frequency climate variability, there are indications that the North Pacific climate system contains significantly enhanced variability on decadal ( $\sim 10$ yr) (e.g., Biondi et al. 1997; Tourre et al. 2001; Chen et al. 2008), bidecadal ( 20 yr) (e.g., Mann and Park 1996; Biondi et al. 1997; Minobe 1999; Tourre et al. 2001; Biondi et al. 2001; Gedalof et al. 2002; d'Orgeville and Peltier 2007; Chen et al. 2008), and multidecadal ( $~ 50-70$ yr) (e.g., Biondi et al. 1997; Minobe 1997, 1999; Gedalof et al. 2002; d'Orgeville and Peltier 2007) time scales. In addition, coupled climate models display variability in the North Pacific that clearly resembles the PDO and exhibit similar enhanced spectral power at bidecadal and decadal time scales (e.g., Latif and Barnett 1994, 1996; Schneider et al. 2002).

One elegant hypothesis is that Pacific decadal variability may reflect the resonant excitation of internal ocean oscillations. A potential candidate is baroclinic basin modes (e.g., Cessi and Primeau 2001). Although direct evidence for their existence is still lacking, basin modes are well-known dynamical "objects" in geophysical fluid dynamics. Basin modes can be considered eigenoscillations of the ocean dynamics in a (semi)enclosed basin. Their main ingredient is long, basin-scale Rossby waves that originate on the eastern boundary of the basin and impinge on the western boundary. Under the ideal circumstances of an inviscid quasigeostrophic fluid on a beta plane in a rectangular basin (e.g., LonguetHiggins 1964; Pedlosky 1965), the coherent arrival at the western boundary of wave crests and troughs generate short Rossby waves that carry the energy back to the eastern boundary to resonantly reenergize the long waves. Resonant conditions exist for Rossby waves whose wave lengths fit into the basin an integral number of times.

However, in reality conditions are less ideal. First of all, latitude-dependent Rossby wave speeds (Cessi and Louazel 2001) and irregular basin geometry (Primeau 2002; LaCasce and Pedlosky 2002; Vikhliaev et al. 2007) generally prevent the coherent arrival of Rossby wave phases. This may lead to destructive interference on the western boundary that attenuates the return signal and, hence, dampens the mode even in the inviscid limit. Still, even weakly damped modes can potentially be excited by stochastic atmospheric forcing (Cessi and Louazel 2001; Liu 2003; Yang et al. 2004) or sustained by weak interaction with the atmosphere (Cessi and Paparella 2001).

Second, the presence of eddy viscosity quickly dampens out short Rossby waves emerging from the western boundary, preventing the return of wave energy through the ocean's interior. However, another mechanism was identified through which energy can be returned to the eastern boundary: when long Rossby waves arrive at the western boundary, they generate a forced gravity wave response (to satisfy mass conservation) that returns energy to the eastern boundary. This possibly reenergizes the long waves (Primeau 2002).

Third, the presence of background flow may impact the basin modes (Spydell and Cessi 2003; Ben Jelloul and Huck 2005; Vikhliaev et al. 2007). In fact, destabilization of Rossby basin modes through interaction with wind-driven gyres is an important source of internal ocean variability in simple ocean models [see Dijkstra and Ghil (2005) for a comprehensive review]. These analyses show that the background flow strongly deforms the basin modes, which now become focused in the region of the main jets. Interestingly, in these studies basin modes are often associated with intermonthly (rather than interannual or longer) time scales on account of the unrealistically small basins employed. In addition to these deformed basin modes, other categories of oscillations are found, namely, the modes related to baroclinic instability of the main jet system: the so-called gyre mode (Jiang et al. 1995), which is generally found with interannual time scales; and recirculating pool modes (Ben Jelloul and Huck 2005), which resemble the interannual mode found by Dawe and Thompson (2005) in their isopycnal ocean model.

Fourth, the stability of Rossby wave fronts, and hence the ability of Rossby waves to maintain coherent wave fronts while crossing the major ocean basins, has been questioned for a turbulent ocean. LaCasce and Pedlosky (2004) suggest that a critical latitude may exist poleward of which large-scale Rossby waves will break up so that coherent wave fronts can only exist in the tropical region. But, obviously this will not prevent the existence of these modes in low-resolution ocean climate models.

The hypothesis that we will address in this study is whether low-frequency climate variability in the North Pacific in a coupled climate model can be traced back to low-order behavior of the subsurface North Pacific Ocean. In particular, we are interested whether we can find evidence for the excitation of classical basin modes, as studied typically in the context of quasigeostrophic or shallow-water models. A first step toward this goal is to investigate low-order behavior in a multicentury integration of a comprehensive coupled climate model, the Community Climate System Model version 3 (CCSM3). To that end, we perform a multivariate principal oscillation pattern (POP) analysis on several model fields to investigate a potential modal origin of the decadal fluctuations in the North Pacific. 


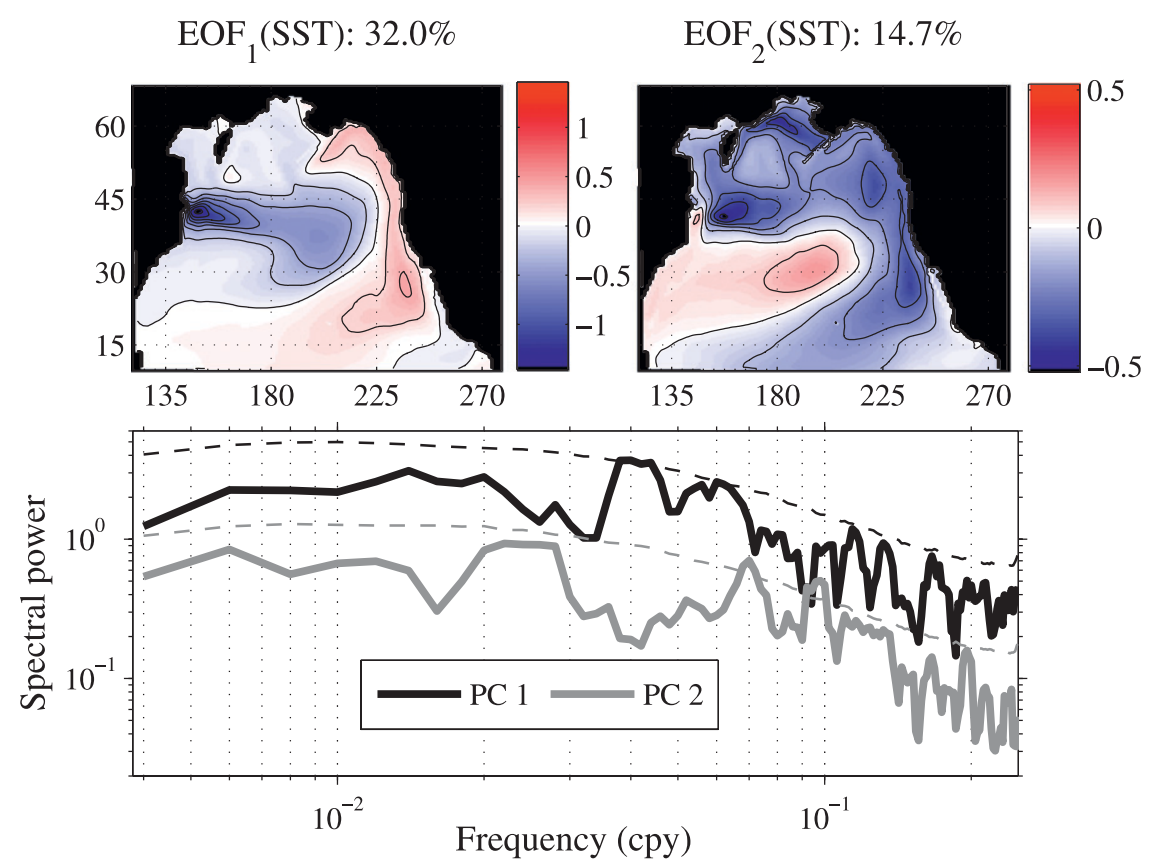

FIG. 1. (top) Dominant EOFs of North Pacific SST variability, contour interval is $0.2^{\circ} \mathrm{C}$ for $\mathrm{EOF}_{1}(\mathrm{SST})$ and $0.1^{\circ} \mathrm{C}$ for $\mathrm{EOF}_{2}(\mathrm{SST})$, and (bottom) the spectra of their associated PCs. Thin lines denotes the 95 th percentiles of 2500 synthetic AR-1 processes with the same parameters as the best fit AR-1 process to the time series. A 5-point Daniell filter (Von Storch and Zwiers 1999 ) is applied to smooth the spectra. Time series are averaged in 2-yr bins to reduce the effect of ENSO. Spectra are offset by subsequent powers of 0.5 for clarity.

One question that needs to be addressed is what characterizes basin modes? In the traditional layered models without background flow basin modes are characterized by (i) basin-scale anomalies in thermocline depth that (ii) display northwestward propagation in agreement with planetary Rossby wave dynamics, and (iii) are energized at the eastern boundary through a forced gravity wave response that homogenizes the pressure perturbations along the boundary of the basin. However, as discussed above, the presence of background flow, bathymetry, realistic continent geometry, and/or nonhomogeneous stratification is likely to modify these traits, possibly beyond recognition. Therefore the main characteristic of an internal ocean oscillation may be a (iv) spatially coherent (modal) oscillation that leaves (v) a detectable spectral signature in the subsurface ocean.

\section{Analysis}

\section{a. Model}

For this study we use output from the Community Climate System Model, version 3 (Collins et al. 2006). The CCSM3 is a fully coupled climate model; it consists of submodels for the different climate components, which communicate through a flux coupler. The ocean component is the Parallel Ocean Program (Smith et al. 2010). For the analysis presented in this paper, we use annually averaged fields from the 500-yr 1990 control integration of CCSM3 (indicated by b30.009). The spatial resolution of the ocean model is nominally $1^{\circ}$ but is nonequidistant, with refinements in the equatorial region and grid distortion in the Northern Hemisphere as a result of displacing the North Pole onto Greenland.

\section{b. SST}

To check whether the CCSM3 model displays realistic North Pacific SST variability, we first determine the dominant statistical modes of variability of SST. To that end we subject the SST data, poleward of $10^{\circ} \mathrm{N}$, to an empirical orthogonal function analysis. The Asian marginal seas are excluded from the analysis. The annual-mean SST data are bin-averaged in 2-yr bins to remove the effect of ENSO, which has a regular biannual cycle in CCSM3 (Deser et al. 2006). The data are then scaled by the square root of the grid box area to remove a bias toward higher latitudes. The EOFs and their associated principal components (PCs) are renormalized so that the PCs have unit variance and the EOFs represent the standard deviation.

The two dominant EOFs of SST (Fig. 1, upper panels) account for $32.0 \%$ and $14.7 \%$ of the interannual 
variability in SST, respectively, and are hence well separated. The dominant EOF $\left[\mathrm{EOF}_{1}(\mathrm{SST})\right]$ shows the familiar anomaly pattern of the PDO, with an area of strong loading extending eastward into the central North Pacific surrounded by a horseshoe-shaped region of opposite sign. In contrast to observations where the variance extrema are located along the subarctic front in the confluence of the Kuroshio and Oyashio and along the subtropical front north of Hawaii (Nakamura et al. 1997), the model displays the strongest variance in the Kuroshio-Oyashio Extension (KOE) area, a bias that is found in many coupled climate models (Furtado et al. 2011).

The spectrum of its $\mathrm{PC}\left[\mathrm{PC}_{1}(\mathrm{SST})\right]$, Fig. 1 lower panel, displays a clear maximum around 0.04 cpy (period of $25 \mathrm{yr}$ ) and a weaker local maximum around 0.06 cpy (17 yr). This confirms the bidecadal character of the variability implied by $\mathrm{EOF}_{1}(\mathrm{SST})$, which can be considered the model equivalent of the PDO (Mantua et al. 1997). However, the 25 -yr peak only marginally exceeds the expectations from a pure red noise process, so evidence for the involvement of a pure oscillatory mode is weak at best.

The second EOF $\left[\mathrm{EOF}_{2}(\mathrm{SST})\right]$ represents the North Pacific gyre oscillation (NPGO) (Di Lorenzo et al. 2008; Furtado et al. 2011), a mode of variability in the North Pacific Ocean. The pattern is consistent with observations (Nakamura et al. 1997), with a local maximum of variance in the central Pacific at latitude $30^{\circ} \mathrm{N}$, surrounded by regions of opposite sign of which an area of maximum variance in the $\mathrm{KOE}$ region stands out. The associated time series $\left[\mathrm{PC}_{2}(\mathrm{SST})\right]$ shows a mostly red spectrum with significantly enhanced energy at 0.07 cpy (14 yr) and 0.09-0.10 cpy (10-11 yr).

Zhong et al. (2008) show that the dominant PC of SST in a comparable present-day integration of a lowerresolution version of CCSM3 (T31_gx3v5) displays significantly enhanced power at periods of 17 and $50 \mathrm{yr}$, but none at $25 \mathrm{yr}$, while d'Orgeville and Peltier (2009) report dominant periodicities of 25 and $17 \mathrm{yr}$ for this same dataset. The reason for the discrepancy between these studies is not clear, but a dominant $17-y r$ periodicity dominating SST variability in this model seems a robust result.

\section{c. Pressure anomalies}

The subsurface variability of the North Pacific is studied in terms of the baroclinic pressure anomaly integrated over the upper $500 \mathrm{~m}, P_{500}$ :

$$
P_{500}=\int_{-500}^{0} p^{\prime} d z=-\int_{-500}^{0} \int_{z}^{0} \rho^{\prime} g d z^{\prime} d z
$$

where $p^{\prime}$ is the anomaly of baroclinic pressure, $\rho^{\prime}$ is the anomaly of potential density, and $g$ is the gravitational constant. To lowest order (and neglecting the Coriolis factor), this can be thought of as a geostrophic streamfunction of the baroclinic circulation in the upper $500 \mathrm{~m}$, where most of the baroclinic variability is found (e.g., Schneider et al. 2002).

The two dominant EOFs of $P_{500}$ (Fig. 2, upper panels) account for $17.1 \%$ and $11.8 \%$ of the variance, respectively. $\mathrm{EOF}_{1}\left(P_{500}\right)$ displays enhanced variance in the southeastern Pacific and along the eastern and northern basin boundary all the way from Baja California to the Sea of Okhotsk. It encircles an area of enhanced variance of opposite sign in the western and central North Pacific. Local maxima are visible at $30^{\circ} \mathrm{N}$, $200^{\circ} \mathrm{E}\left(160^{\circ} \mathrm{W}\right)$ and in the KOE region. The structure of $\mathrm{EOF}_{2}\left(P_{500}\right)$ is characterized by a negative-anomaly tongue stretching southwestward across the subtropical North Pacific. It has a local maximum centered at $25^{\circ} \mathrm{N}, 190^{\circ} \mathrm{E}\left(170^{\circ} \mathrm{W}\right)$.

The spectra of the associated PCs (Fig. 2, lower panel) show no enhanced energy in the $0.04-0.05$ cpy range that could be associated with the 25 -yr spectral peak in the dominant PC of SST (Fig. 1, lower panel). $\mathrm{PC}_{1}\left(P_{500}\right)$ has the highest levels of energy at periods of about 0.06 cpy (17 yr) and displays enhanced spectral power at 0.08 cpy (12 yr) and 0.10 cpy (10 yr), although the peaks are only marginally significant. $\mathrm{PC}_{2}\left(P_{500}\right)$ displays significantly enhanced power only at $0.10 \mathrm{cpy}(10 \mathrm{yr}) . \mathrm{PC}_{1}\left(P_{500}\right)$ is significantly correlated at lag 0 with $\mathrm{PC}_{1}(\mathrm{SST})(0.74)$ and $\mathrm{PC}_{2}(\mathrm{SST})(-0.38) ; \mathrm{PC}_{2}\left(P_{500}\right)$ is weakly correlated $(0.20)$ with $\mathrm{PC}_{1}(\mathrm{SST})$ when lagging by $6 \mathrm{yr}$, while no correlation (nor coherence) is found with $\mathrm{PC}_{2}(\mathrm{SST})$.

Our EOFs do not show obvious correspondence with the two dominant EOFs of the depth of the $26.8 \sigma_{\theta}$ isopycnal, as shown by Alexander et al. (2006) for the same model (albeit for years 350-599 of an extended integration), although 9-yr and 16-yr spectral peaks in the associated PCs suggests that the same dynamics is captured.

\section{d. Multivariate POP analysis}

To search for modal variability in the subsurface North Pacific and its expression in SST, we perform a multivariate principal oscillation pattern analysis on $P_{500}$ and SST. The following preprocessing steps are applied. For each of the fields, annually averaged anomalies of the time series are bandpass filtered using a Parks-McClellan filter of order $N=40$ (Parks and McClellan 1972). The filter passes frequencies between 0.04 and 0.1 cpy (10-25 yr) and transitions to the stop bands at 0.015 cpy $(67 \mathrm{yr})$, and 0.125 ( $8 \mathrm{yr})$. The first $N$ points are discarded. The resulting time series are subsequently area-weighted, then bin-averaged onto a 


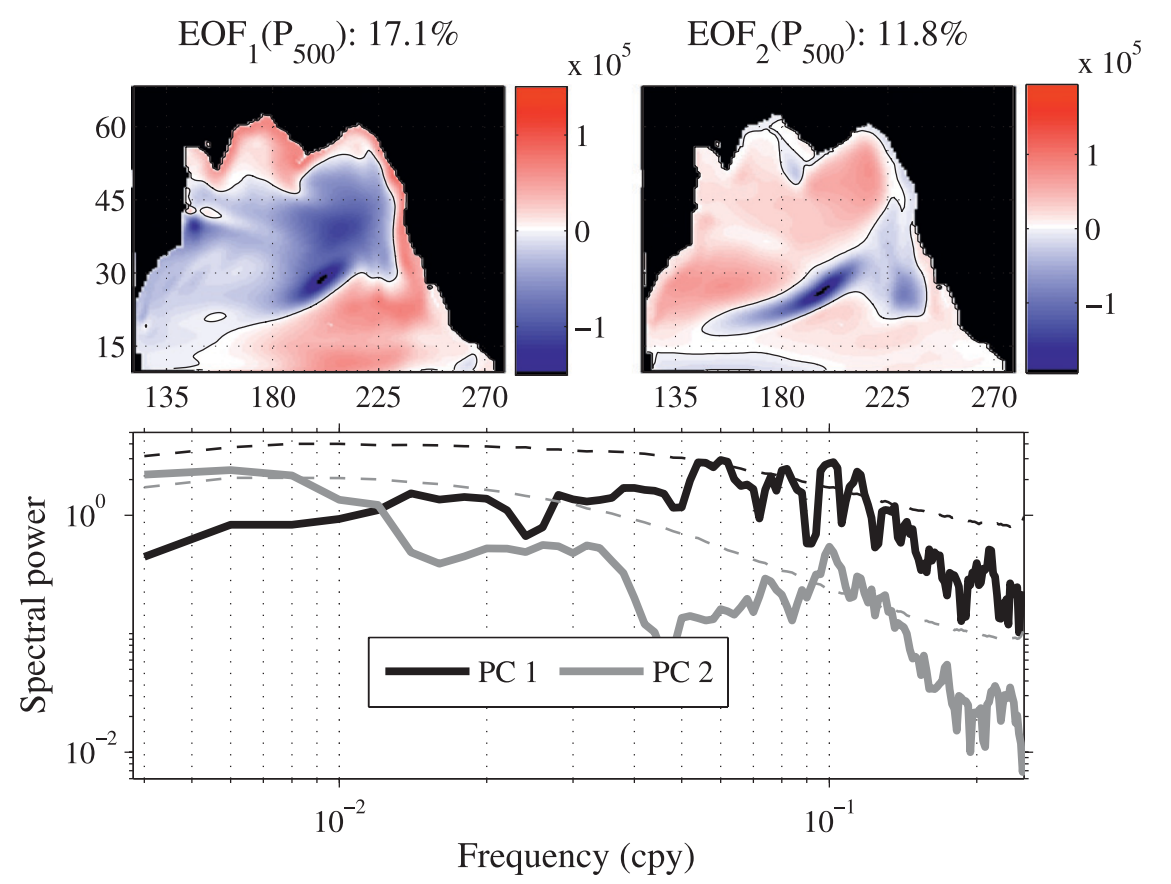

FIG. 2. As in Fig. 1 but for dominant EOFs of $P_{500}$ variability. Contour interval is $0.2\left(10^{5} \mathrm{~Pa} \mathrm{~m}\right)$ for $\mathrm{EOF}_{1}\left(P_{500}\right)$ and $0.4\left(10^{5} \mathrm{~Pa} \mathrm{~m}\right)$ for $\mathrm{EOF}_{2}\left(P_{500}\right)$.

grid of approximately $3^{\circ} \times 3^{\circ}$ to reduce the number of degrees of freedom. Each of the fields is subjected to an EOF prefiltering that is based on a Monte Carlo approach to determine the EOFs that contribute significantly to the signal. To this end, 100 fields are constructed by randomly redistributing the data in space and time, then subjected to an EOF decomposition. This randomization corresponds to a null hypothesis of white noise in space and time. The $M$ EOFs that account for more variance than the 95th percentile of their corresponding Monte Carlo modes are deemed significant. The reconstructed fields are normalized by the variance of the first $M$ EOFs.

The separate fields are then combined into a single data vector and subjected to a joint Monte Carlo EOF truncation, as above. The significant principal components are subjected to the POP analysis (Von Storch et al. 1995). This analysis fits an AR-1 process to the data and determines the eigenmodes of the lagged-covariance matrix. The process yields (complex-valued) modal patterns $p$ and eigenvalues $\sigma$, the latter consisting of a frequency $\operatorname{Im}(\sigma)$ and decay rate $\operatorname{Re}(\sigma)$. The modes are ordered according to their "excitation," which is the variance of their amplitude time series, hence a measure of their dynamical importance (Neumaier and Schneider 2001; Schneider and Neumaier 2001).

To test the physical relevance of the oscillatory POP modes, a coherence analysis is performed between the real and imaginary POP coefficients. These coefficients are estimated here using the least squares method described in Von Storch and Zwiers (1999). For a POP to be deemed physically meaningful, the time series need to be coherent and display a $90^{\circ}$ phase lag in a frequency band consistent with the eigenfrequency of the POP. This phase lag reflects the propagating nature of the POPs and assures the following oscillatory sequence of the spatial pattern: $\operatorname{Re}(p) \rightarrow-\operatorname{Im}(p) \rightarrow$ $-\operatorname{Re}(p) \rightarrow \operatorname{Im}(p) \rightarrow \cdots$.

The POPs determined for the combined $P_{500}-\mathrm{SST}$ system are tabulated in Table 1 . There are 12 oscillatory

TABLE 1. POPs of the combined $P_{500}-\mathrm{SST}$ system, filtered for periods between 10 and $25 \mathrm{yr}$.

\begin{tabular}{rccc}
\hline \hline POP & Period $(\mathrm{yr})$ & Decay $(\mathrm{yr})$ & Excitation $(\%)$ \\
\hline 1 & 11.0 & 72.6 & 8.1 \\
2 & 17.1 & 44.0 & 7.2 \\
3 & 24.6 & 16.6 & 5.8 \\
4 & 26.9 & 13.8 & 5.2 \\
5 & 20.5 & 24.8 & 4.3 \\
6 & 39.5 & 15.5 & 3.6 \\
7 & 14.3 & 22.9 & 3.2 \\
8 & 12.9 & 28.9 & 3.1 \\
9 & 86.1 & 10.5 & 3.1 \\
10 & 15.7 & 34.0 & 2.6 \\
11 & 91.1 & 11.7 & 2.1 \\
12 & 19.1 & 16.3 & 1.6 \\
\hline
\end{tabular}



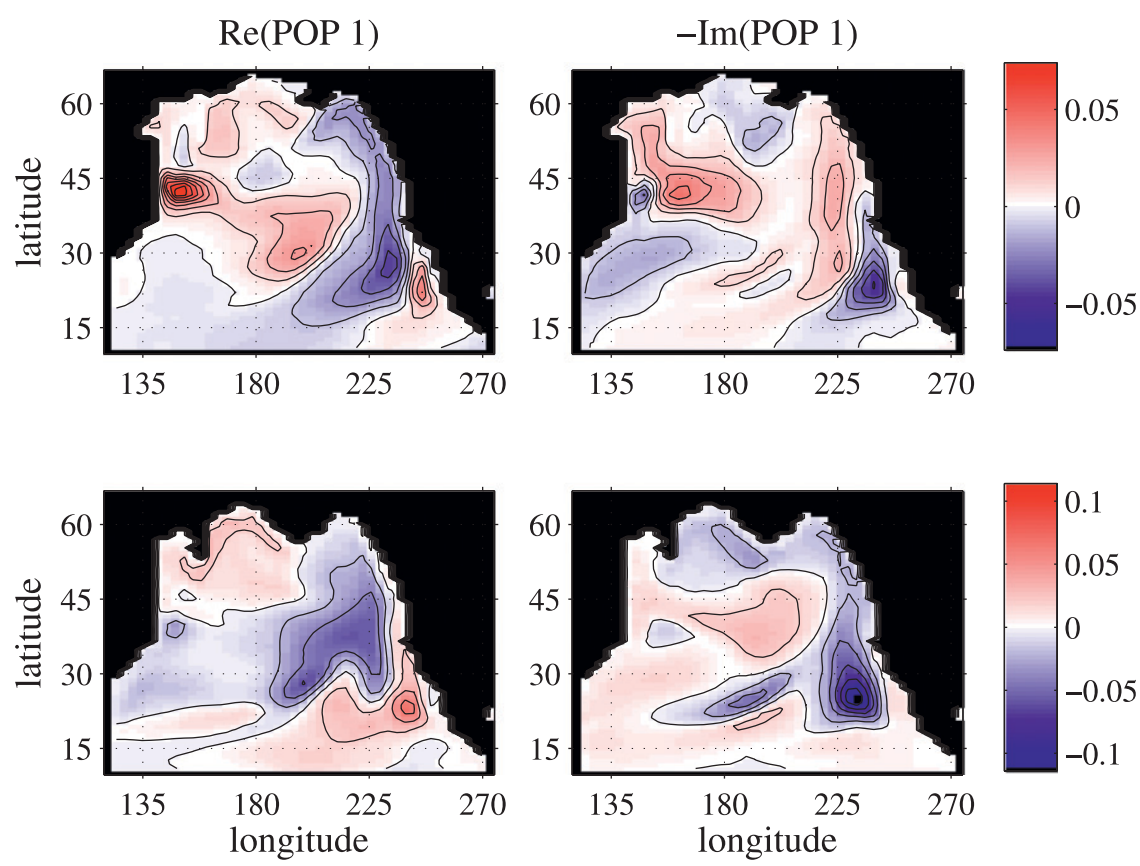

FIG. 3. POP 1 of the joint (top) SST and (bottom) $P_{500}$ fields as discussed in the text. The data were bandpass filtered to retain periods between 10 and $25 \mathrm{yr}$. (left) The real part of the spatial patterns and (right) the (negative) imaginary part: they describe an entire oscillatory cycle according to the sequence: $\operatorname{Re}(p) \rightarrow-\operatorname{Im}(p) \rightarrow-\operatorname{Re}(p) \rightarrow \operatorname{Im}(p) \rightarrow \cdots$. The mode has a 72.6-yr decay time scale and an 11.0-yr oscillation period, and accounts for $8.1 \%$ of the variance.

modes with periods ranging from 11 to $91 \mathrm{yr}$ and decay time scales between 72.6 and 10.5 yr. Because of the bandpass filtering that has been applied, the modes with periodicities outside the filtering window should be regarded with suspicion. Also, the values of the decay time scales should be interpreted with caution. The three dominant POPs have periods of 11.0, 17.1, and $24.6 \mathrm{yr}$, respectively, and their spatial patterns are shown in Figs. 3-5. For these POPs the real and imaginary time series are strongly coherent, and their phase difference is about $-90^{\circ}$ in the filtering window (not shown), suggesting that these modes are physically meaningful and not just noise.

The POPs display rather complex behavior; a description of the several centers of action and multiple directions of propagation is based on an animation of the modal evolution. POPs 1 and 2 display strong SST anomalies emerging in the KOE region, followed by the development of anomalies of the same sign in the central Pacific and crescent-shaped anomalies of opposite sign in the eastern Pacific. A specific center of action seems to be $25^{\circ} \mathrm{N}, 240^{\circ} \mathrm{E}\left(120^{\circ} \mathrm{W}\right)$ in the southeastern Pacific. The SST pattern of mode 3 seems to be mostly a standing pattern with bands of opposite polarities across the Pacific along $20^{\circ}$ and $40^{\circ} \mathrm{N}$ and along $55^{\circ} \mathrm{N}$ in the subpolar North Pacific.
The POPs also have a clear expression in the subsurface pressure field. The main elements of POPs 1 and 2 are quite similar. 1) They feature eastward propagation of anomalies in the central Pacific around $40^{\circ} \mathrm{N}$ (Fig. 6). Upon reaching the eastern Pacific and the California coast anomalies propagate both northward and southward. 2) The southbound anomalies amplify in the eastern Pacific around $25^{\circ} \mathrm{N}, 230^{\circ} \mathrm{E}\left(130^{\circ} \mathrm{W}\right)$ and dissipate around $20^{\circ} \mathrm{N}$. 3) The northbound anomalies make their way northward and westward in the subpolar gyre, and 4) anomalies in $P_{500}$ develop in the central Pacific around $25^{\circ} \mathrm{N}, 195^{\circ} \mathrm{E}\left(165^{\circ} \mathrm{W}\right)$ and subsequently propagate southwestward. For both modes the anomalies decay before reaching the western basin boundary. The main difference between POPs 1 and 2 is that for POP 1 the eastward anomalies in $P_{500}$ develop in the central Pacific around $200^{\circ} \mathrm{E}\left(160^{\circ} \mathrm{W}\right)$, while POP 2 clearly displays the anomalies emerging from the KOE region. For POP 3 the anomalies in $P_{500}$ do not display well-defined propagation patterns.

Clearly, the modes are not readily identifiable as classical baroclinic basin modes: there is no evidence for the simple picture of basin-scale anomalies in $P_{500}$ that arise on the eastern boundary and propagate northwestward in accordance with simple Rossby wave dynamics. 

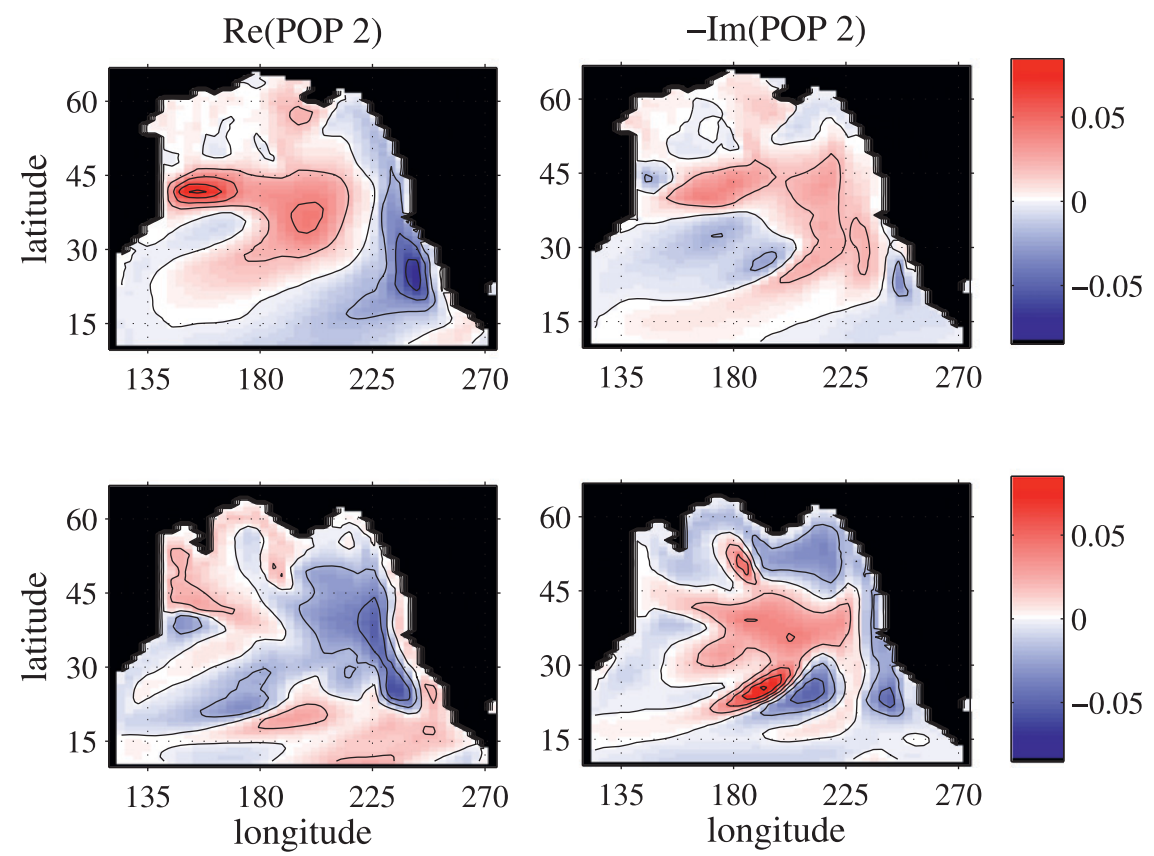

FIG. 4. As in Fig. 3 but for POP 2. The mode has a 44.0-yr decay time scale and a 17.1-yr oscillation period, and accounts for $7.2 \%$ of the variance.

e. Relationship between POPs and dominant modes of SST and pressure

To study how the POPs relate to the dominant statistical modes of SST and $P_{500}$ variability, we calculate the coherences between the POP time series and the principal components presented in the previous sections. Figure 7 shows that POP 1 is strongly coherent with the PCs of $P_{500}$, and to a lesser extent with $\mathrm{PC}_{1}(\mathrm{SST})$. Coherences are optimal at the decadal period, consistent
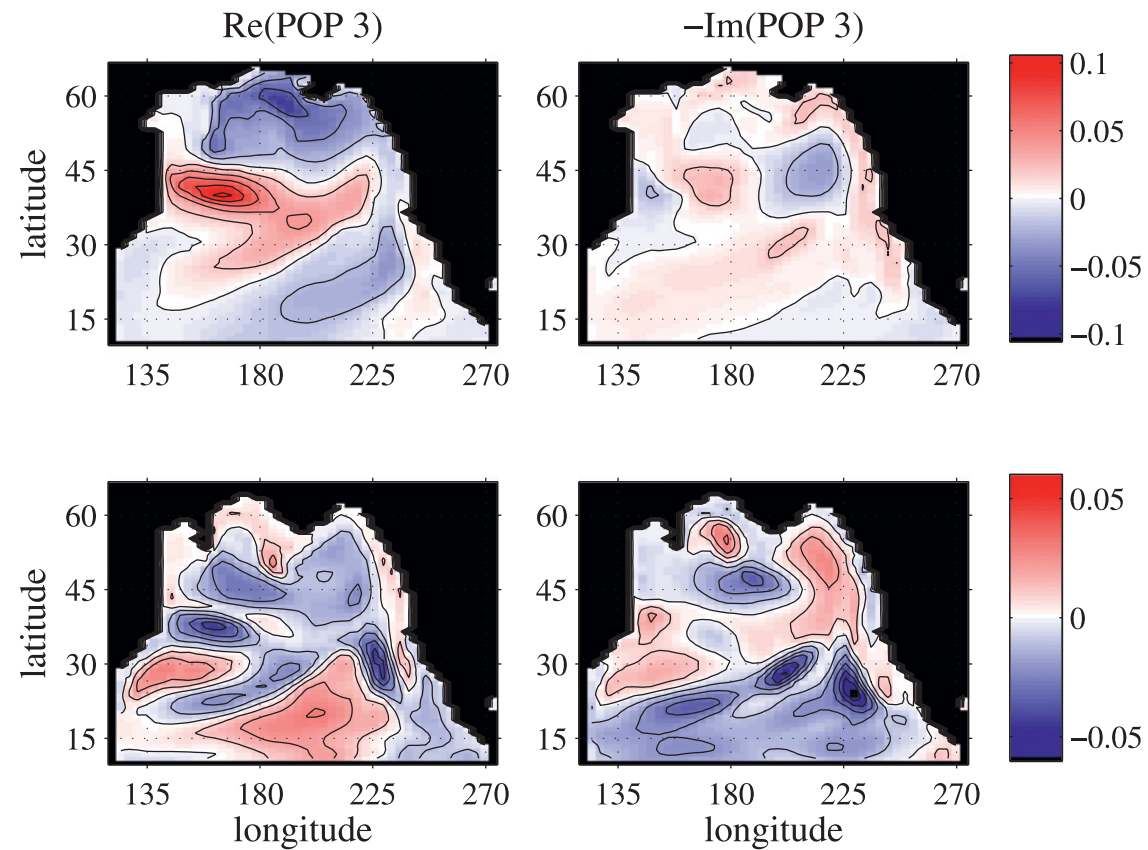

FIG. 5. As in Fig. 3 but for POP 3. The mode has a 16.6-yr decay time scale and a 24.6-yr oscillation period, and accounts for $5.8 \%$ of the variance. 


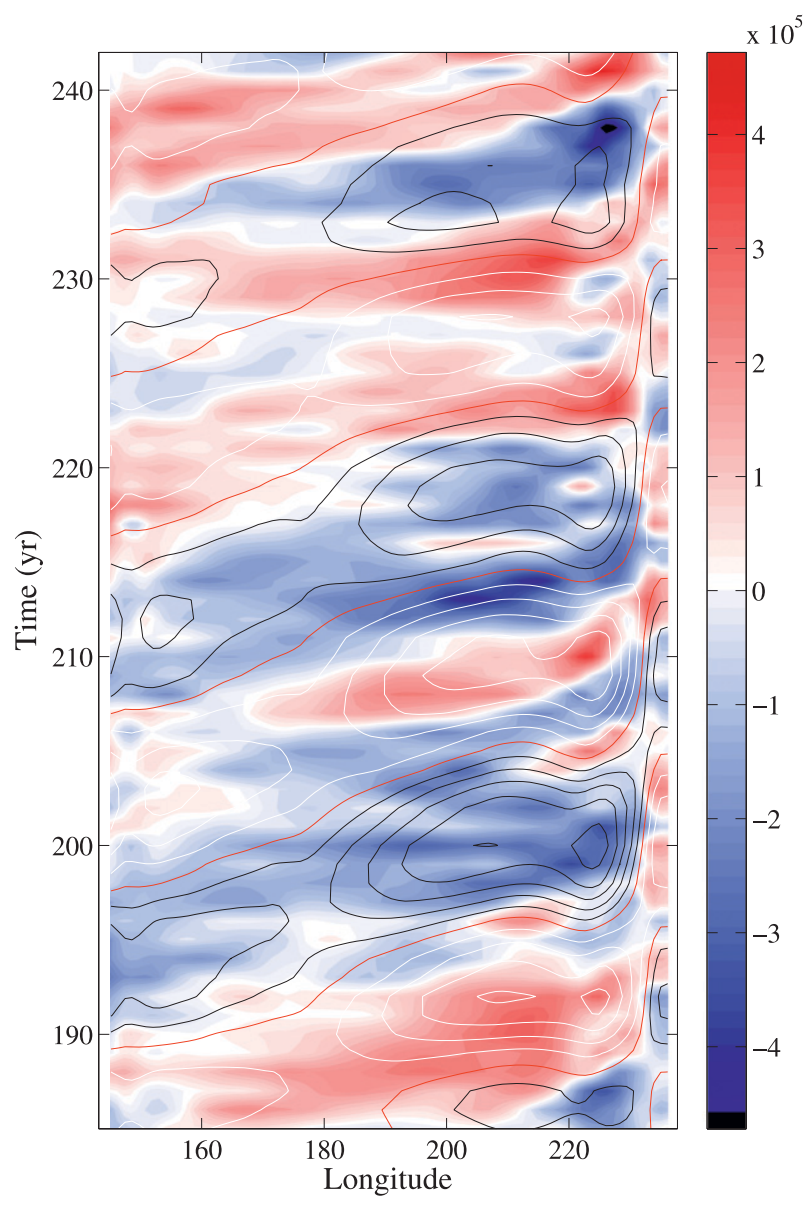

FIG. 6. Hovmöller diagram showing $P_{500}$ during a 55-yr segment along $42^{\circ} \mathrm{N}$. Contours are the corresponding reconstruction for POP 2, with contour interval $2 \times 10^{4} \mathrm{~Pa} \mathrm{~m}$. Black, red, and white contours represent negative, zero, and positive values, respectively.

with the 11-yr period of the POP, as well as with the decadal peaks in the spectra of $\mathrm{PC}_{1}\left(P_{500}\right)$ and $\mathrm{PC}_{2}\left(P_{500}\right)$ (Fig. 2). POP 2 is coherent with the dominant PCs of SST and $P_{500}$. Significant coherences are found in the bidecadal range between 13 and 23 yr with maximum coherences close to the 17-yr period of the POP, the 17-yr peak in the spectrum of $\mathrm{PC}_{1}\left(P_{500}\right)$ (Fig. 2c), and the marginally enhanced energy in $\mathrm{PC}_{1}(\mathrm{SST})$ at that time scale. POP 3, with a 25 -yr period, is a prime candidate to account for the enhanced energy around $25 \mathrm{yr}$ of $\mathrm{PC}_{1}(\mathrm{SST})$. Figure 7 shows that its time series is only weakly coherent with $\mathrm{PC}_{1}\left(P_{500}\right)$, and even less so with $\mathrm{PC}_{1}(\mathrm{SST})$ at periods around $20 \mathrm{yr}$.

This association between the time series of POPs 1 and 2 and the dominant statistical modes of subsurface pressure suggests that POPs 1 and 2 indeed reflect two distinct internal ocean oscillations. POP 1 represents variability on decadal time scale that is clearly captured by the two dominant EOFs of $P_{500}$ and projects weakly
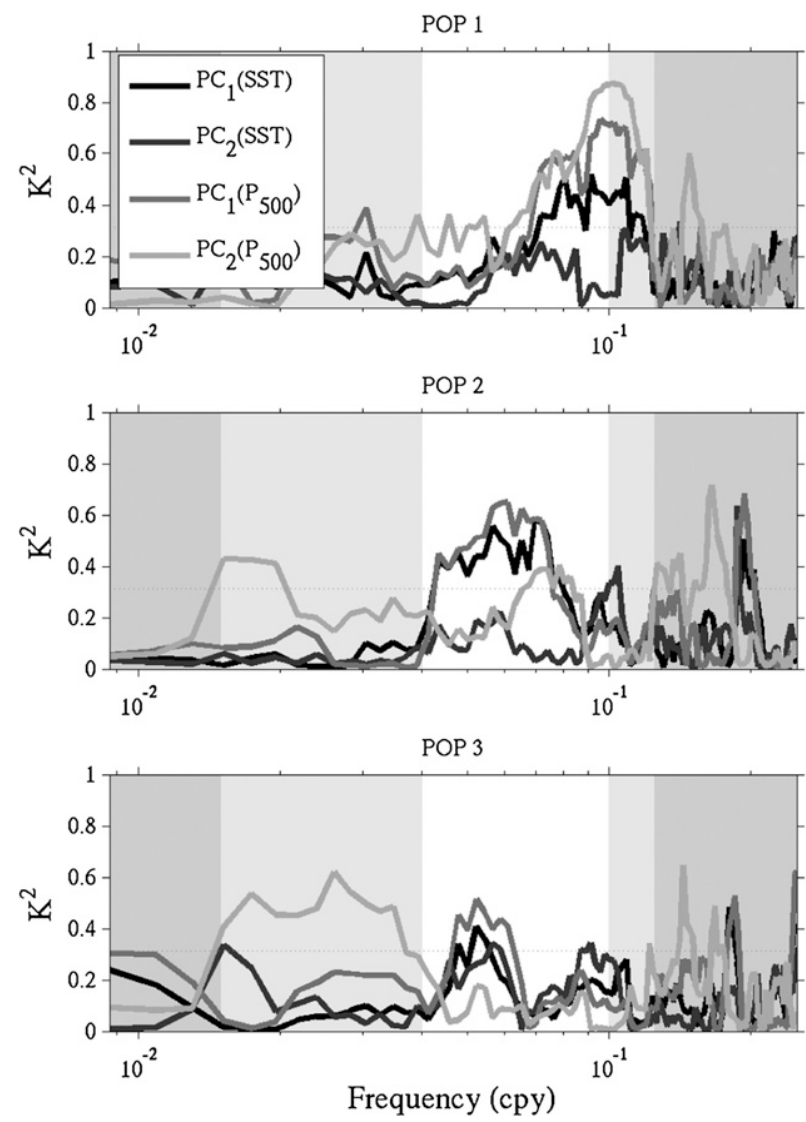

FIG. 7. (Squared) coherences between the (complex-valued) POP coefficients and the dominant PCs of SST, and the dominant PCs of the integrated pressure anomaly $P_{500}$. A 9-point Daniell filter is used to smooth the spectra. White area denotes the pass band of the Parks-McClellan filter, while dark and light gray areas denote the stop and transition bands, respectively. Dotted lines indicate $95 \%$ confidence level of a significant coherence.

on the dominant EOF of SST variability. POP 2 represents bidecadal variability with a $17-\mathrm{yr}$ time scale that has an expression in the dominant EOF of $P_{500}$ and projects onto the dominant mode of SST as well.

\section{f. Boundary pressure}

To further explore the variability of the ocean interior, we consider another characteristic of basin modes, namely the homogenization of the modal pressure field along the basin boundary. Figure 8 shows the spectrum of the pressure anomaly time series $P_{\text {east }}$, which is constructed by averaging $P_{500}$ over the easternmost ocean points of the North Pacific from the equator to the Gulf of Alaska.

Evidently, there is no enhanced energy in the pressure time series at the 25 -yr period that characterized the spectrum of the dominant PC of SST (Fig. 1b). However, $P_{\text {east }}$ does display significant spectral peaks at periods of 


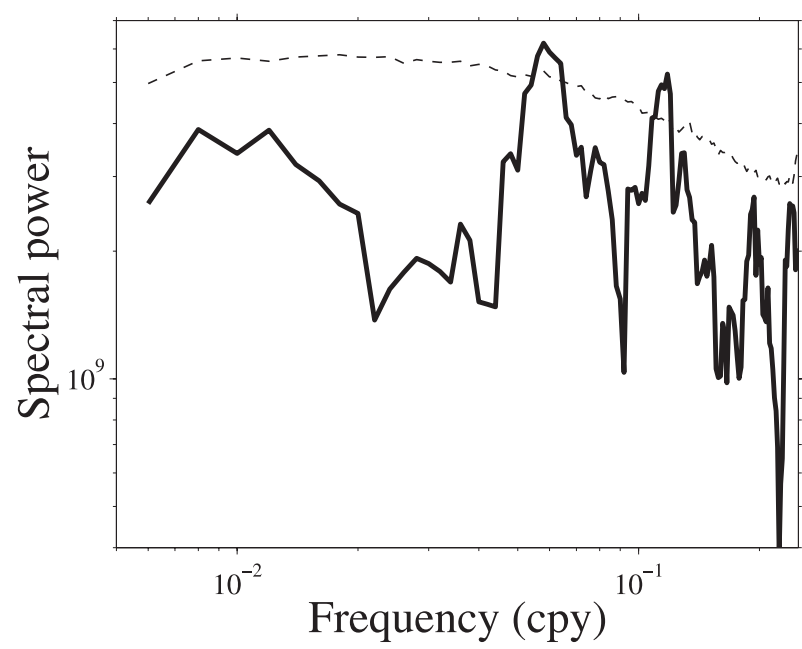

FIG. 8. Spectrum of the time series of eastern boundary pressure, $P_{\text {east }}$.

17.2 and $8.5 \mathrm{yr}$. In fact, $P_{\text {east }}$ is significantly correlated $(0.65)$ with the $\mathrm{PC}_{1}\left(P_{500}\right)$, while a maximum correlation of 0.21 is found with $\mathrm{PC}_{2}\left(P_{500}\right)$ when lagging by $7 \mathrm{yr}$. But most importantly, $P_{\text {east }}$ is significantly coherent with the POP 2 time series around the $17-y r$ period (Fig. 9). No such coherences are found with the POP 1 time series, so the 8.5-yr peak in the spectrum of $P_{\text {east }}$ does not seem to be associated with this decadal mode.

To study whether $P_{\text {east }}$ reflects a homogenization of pressure around the entire perimeter of the North Pacific basin, we determined the regression of the $P_{\text {east }}$ series on the pressure anomaly in the entire North Pacific basin (Fig. 10). The plot shows a strong relation between $P_{\text {east }}$ and pressure anomalies in a narrow strip along the eastern and northern rim of the North Pacific ending in the sea of Okhotsk, a band of positive values stretching westward from the Baja California, and a tongue of positive regressions along the equator. A pool of negative values is found in the central Pacific and along the western boundary of the Pacific. The pattern visually resembles the imaginary part of POP 2 , the time series of which was found to be coherent with $P_{\text {east. }}$. For this signal to be interpreted as a circum-Pacific boundary pressure adjustment to Rossby wave fronts arriving at the western boundary, we would have expected a positive regression along the entire rim of the Pacific, and specifically along the equator. The fact that pressure anomalies of opposite sign are found along the western edge of the Pacific is therefore not consistent with the basin mode hypothesis.

To bring out the relation between eastern boundary pressure and the two dominant POP modes more clearly, we calculated the (squared) coherencies and phases between the $P_{\text {east }}$ time series and $P_{500}$ in the entire North

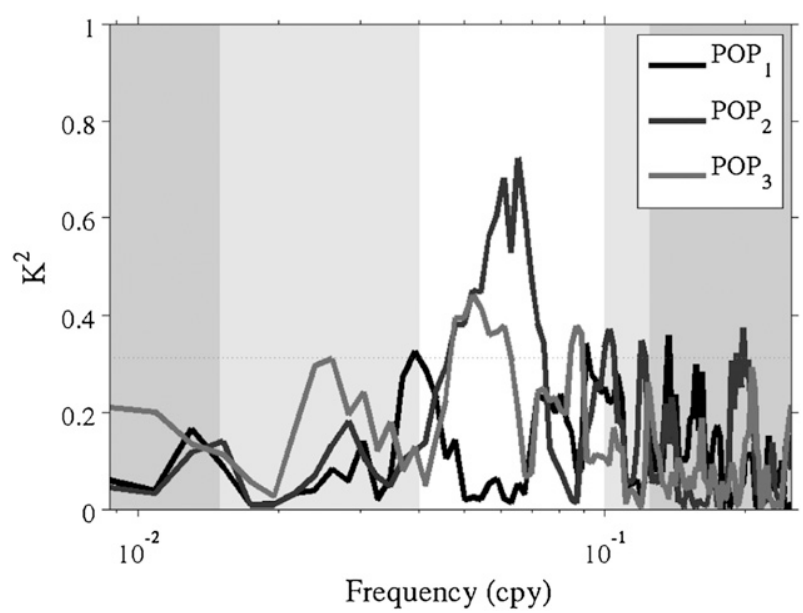

FIG. 9. As in Fig. 7 but for the (squared) coherence between the POP time series and $P_{\text {east }}$.

Pacific basin and show the coherency values for the 17-yr and 10-yr periodicities (Fig. 11). The coherence pattern at $17 \mathrm{yr}$ shows much of the same features identified in the description of POP 2. Most importantly, there is a corridor of significant coherences stretching across the North Pacific around $40^{\circ} \mathrm{N}$. It features a steady eastward phase propagation from the KOE region into the eastern North Pacific, consistent with the Hovmöller diagram in Fig. 6. From there the phase lines turn northward into the Gulf of Alaska. Upon reaching the Aleutians, significant coherences propagate quickly westward along the northern rim of the Pacific basin, back toward the KOE region. This picture suggests the possibility of a stochastically forced, resonant loop where density (and pressure) anomalies are advected by the subpolar gyre, possibly with some help from a forced coastally trapped

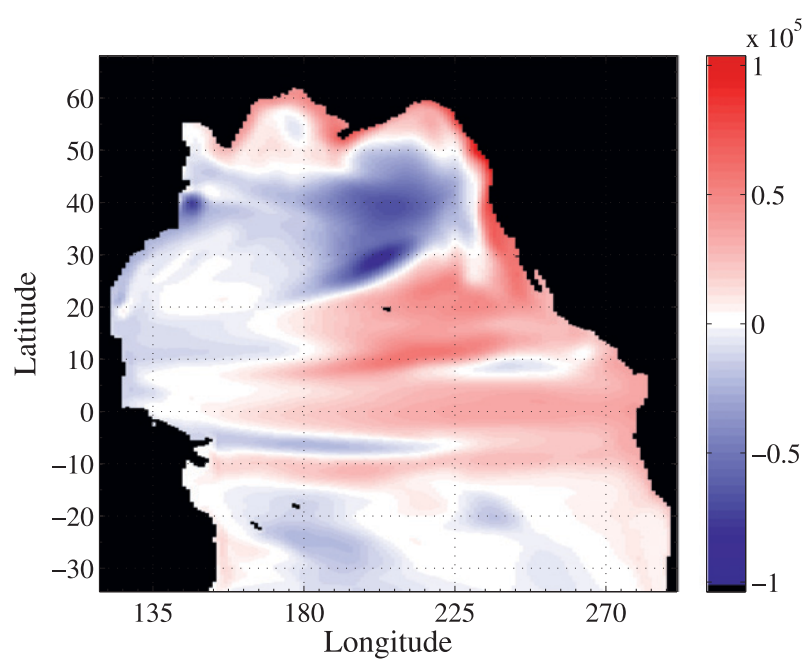

FIG. 10. Linear regression of the (normalized) $P_{\text {east }}$ time series on $P_{500}$. 
a)

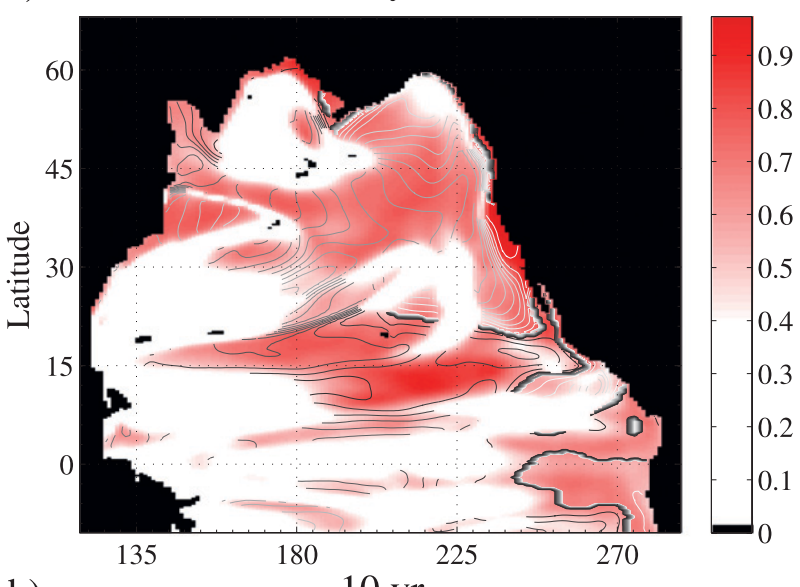

b)

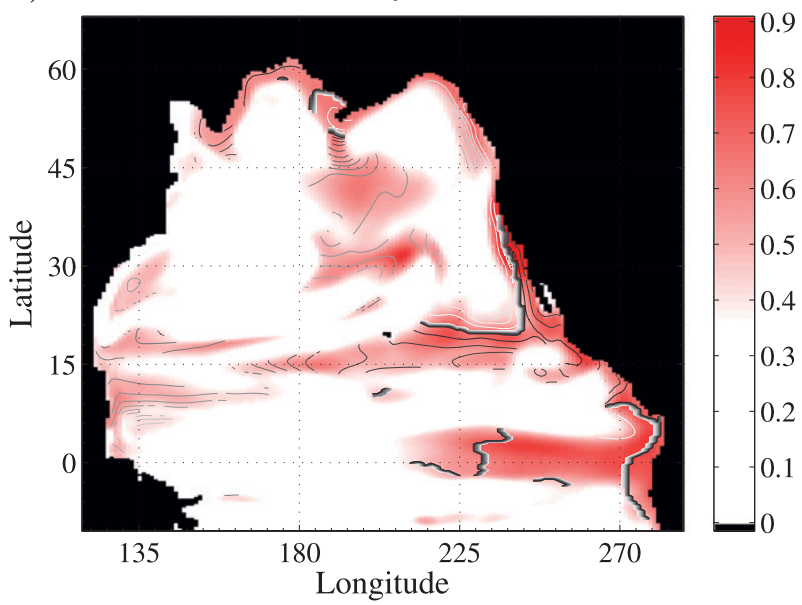

FIG. 11. Coherence between $P_{\text {east }}$ and $P_{500}$, for the (a) 17 -yr and (b) 10 -yr periods. Only (squared) coherencies that exceed 0.4 are significant and shaded. Phase lines are drawn every $15^{\circ}$ from $0^{\circ}$ (white) to $360^{\circ}$ (black), with positive phase meaning $P_{500}$ leads $P_{\text {east. }}$. So, a decreasing lead of $P_{500}$ on $P_{\text {east }}$ is indicated by progressively lighter contours.

gravity wave response along the northern rim of the North Pacific (Primeau 2002).

It is not fully clear how the arrival of the pressure anomalies and the boundary pressure fluctuations on the 17-yr time scale are related. Although eastward propagation is detectable all the way to the coast between $30^{\circ}$ and $50^{\circ} \mathrm{N}$, a crowding of phase lines indicates that it takes the pressure anomalies about $7 \mathrm{yr}\left(150^{\circ}\right)$ to bridge the final $10^{\circ}$ in longitude to reach the boundary. This holding area is also a region of reduced coherences between $P_{\text {east }}$ and $P_{500}$.

The comparable plot for the 10-yr periodicity does not show similar widespread coherences (Fig. 11b). The dominant feature is a tongue of significant coherences that emanates from the coast and stretches westward into the central Pacific between $10^{\circ}$ and $20^{\circ} \mathrm{N}$. It is likely that the coherence with the pressure anomalies in the equatorial cold tongue region is independent of the processes responsible for POP 1 since the mode does not show any obvious connections with the eastern equatorial Pacific (Fig. 3). Furthermore, this pattern, as well as the apparent gravity wave response around the rim of most of the North Pacific (not shown), stands out better when looking at the coherences at $8.5 \mathrm{yr}$, which is the period associated with the enhanced spectral power in the time series of $P_{\text {east }}$ (Fig. 8). This suggests an equatorial origin for the decadal variability in $P_{\text {east }}$. As is the case for the 17-yr variability, despite the closely packed isophase lines off northern North America, the phase propagation is eastward and is therefore inconsistent with the excitation of westward propagating Rossby waves by boundary pressure fluctuations.

\section{Summary and discussion}

In the analysis presented here we sought evidence for the involvement of internal ocean oscillations in Pacific decadal variability. To recall, our criteria for identifying a classical Rossby basin mode are that the pattern should exhibit (i) basin-scale anomalies in thermocline depth that (ii) display northwestward propagation in agreement with planetary Rossby wave dynamics, and (iii) are energized by pressure perturbations along the eastern boundary of the basin. For more general internal ocean oscillations (e.g., basin modes that have been modified beyond recognition by the background circulation) we should expect to find at least (iv) a spatially coherent (modal) oscillation that leaves (v) a detectable spectral signature in subsurface ocean variables.

We subjected the output from a 500-yr control integration of the CCSM3 to a series of statistical analyses. First, we confirmed that CCSM3 reproduces PDO-like variability: the dominant EOF of North Pacific SST displays a spatial pattern similar to the observational PDO. In addition, its associated time series $\left[\mathrm{PC}_{1}(\mathrm{SST})\right]$ has its strongest variance on bidecadal time scales with a (marginally) significant spectral peak around $25 \mathrm{yr}$ and enhanced energy around 17 yr. However, no enhanced energy was found at the 25 -yr time scale in the dominant PCs of subsurface pressure or in the time series of eastern boundary pressure. Although POP 3, with an oscillation period of $24.6 \mathrm{yr}$, emerged as the prime candidate to account for this 25 -yr signal, coherences between the POP 3 time series and the dominant PCs of SST and $P_{500}$ were weak. We therefore conclude that it is unlikely that the dominant 25-yr signal of the model PDO is related to an internal ocean oscillation.

In contrast, POPs 1 and 2 with nominal oscillation periods of 11.0 and $17.1 \mathrm{yr}$, respectively, were found to 
have a significant spectral signature in the pressure field of the subsurface North Pacific, and hence satisfy criteria (iv) and (v) above. However, although they display large-scale anomalies in subsurface pressure (i), they lack the characteristic northwestward propagation associated with Rossby waves (ii). POP 2 does have a clear relation with pressure fluctuations on the eastern boundary, suggesting that, in principle, it could be energized on the eastern boundary, but no synchronous pressure variations were found on the western or equatorial boundaries of the Pacific (iii). Thus, based on our analysis, we conclude that, likely, POPs 1 and 2 reflect the excitation of internal ocean oscillations, although there is no indication of a link to basin mode dynamics.

The predominant eastward propagation of signals across the North Pacific is inconsistent with the analysis of Schneider et al. (2002), who analyzed the pressure anomalies associated with the dominant mode of decadal variability in another coupled climate model. They found a westward propagation instead, which they attributed to Rossby waves forced by variability in Ekman pumping. However, the eastward propagation of pressure anomalies associated especially with the 17-yr mode, a signal robustly found in lower-resolution versions of the same model, seems to suggest an advective mechanism instead, involving anomalies propagating around the subpolar gyre, as suggested by d'Orgeville and Peltier (2009). Dynamical theories of oceanic adjustment to wind stress curl usually assume zero pressure fluctuations on the eastern basin boundary (e.g., Schneider and Miller 2001), so an interior source for eastern boundary pressure fluctuations would be of great interest to studies of sea level variability. A more detailed analysis into what sets the specific 17-yr time scale, and how the mode is excited through interaction with the atmosphere, is currently in progress.

Another interesting result is that the NPGO, which is represented by the second EOF of SST in this model, could not be associated with a dominant POP of the coupled $P_{500}-\mathrm{SST}$ system. Despite some significant spectral peaks in its $\mathrm{PC}$ at 14 and $10 \mathrm{yr}$ and a significant correlation with the dominant PC of $P_{500}$, no strong link with a POP time series was found. This is in contrast to the conclusion of Furtado et al. (2011), who suggest that the second mode may reflect the excitation of an internal ocean oscillation. They base this conclusion on the analysis of a large ensemble of coupled climate models, by showing that the NPGO has longer memory and is less strongly coupled to atmospheric circulation variability than the PDO; the CCSM3 in particular is among seven of the models in which direct atmospheric forcing fails to explain NPGO variability. The reason for this discrepancy is unclear.
Acknowledgments. This research was supported by NSF through Grants 928473 and 928395 , and by the Regional and Global Climate Modeling Program of the U.S. Department of Energy Office of Science. Los Alamos National Laboratory is operated by the Los Alamos National Security, LLC, for the National Nuclear Security Administration of the U.S. Department of Energy under Contract DE-AC52-06NA25396. For this study we used the Matlab routine EOF by David Kaplan (UCSC) and the ARFIT package by Schneider (Caltech) and Neumaier (University of Vienna). The CCSM 3.0 b30.009 data were obtained from the Earth System Grid. We thank three anonymous reviewers for their constructive comments.

\section{REFERENCES}

Alexander, M., and Coauthors, 2006: Extratropical atmosphereocean variability in CCSM3. J. Climate, 19, 2496-2525.

Ben Jelloul, M., and T. Huck, 2005: Low-frequency basin modes in a two-layer quasigeostrophic model in the presence of a mean gyre flow. J. Phys. Oceanogr., 35, 2167-2186.

Biondi, F., C. B. Lange, M. K. Hughes, and W. H. Berger, 1997: Inter-decadal signals during the last millennium (AD 11171992) in the varve record of Santa Barbara basin, California. Geophys. Res. Lett., 24, 193-196.

—, A. Gershunov, and D. R. Cayan, 2001: North Pacific decadal climate variability since 1661 . J. Climate, 14, 5-10.

Cessi, P., and S. Louazel, 2001: Decadal oceanic response to stochastic wind forcing. J. Phys. Oceanogr., 31, 3020-3029.

— atmosphere coupling. Geophys. Res. Lett., 28, 2437-2440.

-, and F. Primeau, 2001: Dissipative selection of low-frequency modes in a reduced-gravity basin. J. Phys. Oceanogr., 31, 127137.

Chen, J., A. D. Del Genio, B. E. Carlson, and M. G. Bosilovich, 2008: The spatiotemporal structure of twentieth-century climate variations in observations and reanalyses. Part II: Pacific pan-decadal variability. J. Climate, 21, 2634-2650.

Collins, W. D., and Coauthors, 2006: The Community Climate System Model version 3 (CCSM3). J. Climate, 19, 21222143.

Dawe, J. T., and L. Thompson, 2005: Viscosity-dependent internal variability in a model of the North Pacific. J. Phys. Oceanogr., 35, 747-756.

Deser, C., A. Capotondi, R. Saravanan, and A. Phillips, 2006: Tropical Pacific and Atlantic climate variability in CCSM3. J. Climate, 19, 2451-2481.

Dijkstra, H. A., and M. Ghil, 2005: Low-frequency variability of the large-scale ocean circulation. Rev. Geophys., 43, RG3002, doi:10.1029/2002RG000122.

Di Lorenzo, E., and Coauthors, 2008: North Pacific gyre oscillation links ocean climate and ecosystem change. Geophys. Res. Lett., 35, L08607, doi:10.1029/2007GL032838.

d'Orgeville, M., and W. R. Peltier, 2007: On the Pacific decadal oscillation and the Atlantic multidecadal oscillation: Might they be related? Geophys. Res. Lett., 34, L23705, doi:10.1029/ 2007 GL031584.

_ and _ 2009: Implications of both statistical equilibrium and global warming simulations with CCSM3. Part I: On the 
decadal variability in the North Pacific basin. J. Climate, 22, 5277-5297.

Frankignoul, C., and K. Hasselmann, 1977: Stochastic climate models. Part II: Application to sea-surface temperature anomalies and thermocline variability. Tellus, 29, 289-305.

—_, P. Müller, and E. Zorita, 1997: A simple model of the decadal response of the ocean to stochastic wind forcing. J. Phys. Oceanogr., 27, 1533-1546.

Furtado, J. C., E. Di Lorenzo, N. Schneider, and N. A. Bond, 2011: North Pacific decadal variability and climate change in the IPCC AR4 models. J. Climate, 24, 3049-3067.

Gedalof, Z., N. J. Mantua, and D. L. Peterson, 2002: A multicentury perspective of variability in the Pacific decadal oscillation: New insights from tree rings and coral. Geophys. Res. Lett., 29, 2204, doi:10.1029/2002GL015824.

Hasselmann, K., 1976: Stochastic climate models. I: Theory. Tellus, 28, 473-485.

Jiang, S., F.-F. Jin, and M. Ghil, 1995: Multiple equilibria, periodic, and aperiodic solutions in a wind-driven, double-gyre, shallowwater model. J. Phys. Oceanogr., 25, 764-786.

LaCasce, J. H., and J. Pedlosky, 2002: Baroclinic Rossby waves in irregular basins. J. Phys. Oceanogr., 32, 2828-2847.

— and _ 2004: The instability of Rossby basin modes and the oceanic eddy field. J. Phys. Oceanogr., 34, 2027-2041.

Latif, M., and T. Barnett, 1994: Causes of decadal climate variability over the North Pacific and North America. Science, 266, 634-637.

—_, and — 1996: Decadal climate variability over the North Pacific and North America: Dynamics and predictability. J. Climate, 9, 2407-2423.

Liu, Z., 2003: Tropical ocean decadal variability and resonance of planetary wave basin modes. Part I: Theory. J. Climate, 16, 1539-1550.

Longuet-Higgins, M. S., 1964: Planetary waves on a rotating sphere. Proc. Roy. Soc. London, 279A, 446-473.

Mann, M. E., and J. Park, 1996: Joint spatiotemporal modes of surface temperature and sea level pressure variability in the Northern Hemisphere during the last century. J. Climate, 9, 2137-2162.

Mantua, N. J., S. R. Hare, Y. Zhang, J. M. Wallace, and R. C. Francis, 1997: A Pacific interdecadal climate oscillation with impacts on salmon production. Bull. Amer. Meteor. Soc., 78, 1069-1079.

Miller, A. J., and N. Schneider, 2000: Interdecadal climate regime dynamics in the North Pacific Ocean: Theories, observations and ecosystem impacts. Prog. Oceanogr., 47, 355-379.

Minobe, S., 1997: A 50-70 year climatic oscillation over the North Pacific and North America. Geophys. Res. Lett., 24, 683-686. , 1999: Resonance in bidecadal and pentadecadal climate oscillations over the North Pacific: Role in climatic regime shifts. Geophys. Res. Lett., 26, 855-858.
Nakamura, H., G. Lin, and T. Yamagata, 1997: Decadal climate variability in the North Pacific during the recent decades. Bull. Amer. Meteor. Soc., 78, 2215-2225.

Neumaier, A., and T. Schneider, 2001: Estimation of parameters and eigenmodes of multivariate autoregressive models. $A C M$ Trans. Math. Software, 27, 27-57.

Parks, T. W., and J. H. McClellan, 1972: Chebyshev approximation for nonrecursive digital filters with linear phase. IEEE Trans. Circuit Theory, 19, 189-194.

Pedlosky, J., 1965: A study of the time-dependent ocean circulation. J. Atmos. Sci., 22, 267-272.

Primeau, F. W., 2002: Long Rossby wave basin-crossing time and the resonance of low-frequency basin modes. J. Phys. Oceanogr., 32, 2652-2665.

Qiu, B., 2003: Kuroshio Extension variability and forcing of the Pacific decadal oscillations: Responses and potential feedback. J. Phys. Oceanogr., 33, 2465-2482.

_ , and S. Chen, 2005: Variability of the Kuroshio Extension jet, recirculation gyre, and mesoscale eddies on decadal time scales. J. Phys. Oceanogr., 35, 2090-2103.

Schneider, N., and A. J. Miller, 2001: Predicting western North Pacific Ocean climate. J. Climate, 14, 3997-4002.

,$- \ldots$, and D. W. Pierce, 2002: Anatomy of North Pacific decadal variability. J. Climate, 15, 586-605.

Schneider, T., and A. Neumaier, 2001: Algorithm 808: ARfit-A Matlab package for the estimation of parameters and eigenmodes of multivariate autoregressive models. ACM Trans. Math. Software, 27, 58-65.

Smith, R., and Coauthors, 2010: The Parallel Ocean Program (POP) reference manual. Los Alamos National Laboratory Tech. Rep. LAUR-10-01853, 141 pp.

Spydell, M., and P. Cessi, 2003: Baroclinic modes in a two-layer basin. J. Phys. Oceanogr., 33, 610-622.

Tourre, Y. M., B. Rajagopalan, Y. Kushnir, M. Barlow, and W. B. White, 2001: Patterns of coherent decadal and interdecadal climate signals in the Pacific basin during the 20th century. Geophys. Res. Lett., 28, 2069-2072.

Vikhliaev, Y., P. Schopf, T. DelSole, and B. Kirtman, 2007: Finding multiple basin modes in a linear ocean model. J. Atmos. Oceanic Technol., 24, 1033-1049.

Von Storch, H., and F. W. Zwiers, 1999: Statistical Analysis in Climate Research. Cambridge University Press, 484 pp.

_, G. Bürger, R. Schnur, and J.-S. Von Storch, 1995: Principal oscillation patterns: A review. J. Climate, 8, 377-400.

Yang, H., Z. Liu, and Q. Zhang, 2004: Tropical ocean decadal variability and resonance of planetary wave basin modes. Part II: Numerical study. J. Climate, 17, 1711-1721.

Zhong, Y., Z. Liu, and R. Jacob, 2008: Origin of Pacific multidecadal variability in the Community Climate System Model, version 3 (CCSM3): A combined and dynamical assessment. J. Climate, 21, 114-133. 